\title{
Effect of Microwave Pretreatment on Extraction Yield and Quality of Catfish Oil in Northern Thailand
}

\author{
Thitiphan Chimsook ${ }^{1, a}$ and Waranya Wannalangka ${ }^{1}$ \\ ${ }^{1}$ Faculty of Science, Department of Chemistry, Applied Chemistry, Maejo University, Chiang Mai, Thailand 50290
}

\begin{abstract}
The effect of microwave pretreatment of catfish processing waste on oil recovery and quality was investigated. Fish oil was extracted using the enzymatic hydrolysis using alcalase enzyme after the microwave pretreatment. The effect of microwave power and microwave pretreatment times was evaluated. The results revealed that a highest yield of $9.25 \%$ when catfish waste was treated at $110 \mathrm{~W}$ for $60 \mathrm{~s}$. This condition was found as the most appropriate condition of microwave pretreatment since it decreased the extraction time from $150 \mathrm{~min}$ to up to $30 \mathrm{~min}$. Analysis of oil quality indices (e.g. acid value, $p$-anisidine value, peroxide value) extracted by microwave pretreatment and non-pretreatment indicated that catfish oil from both processes has comparatively similar fatty acids composition. In addition, catfish oil was extracted by microwave pretreatment and enzymatic hydrolysis had lower lipid oxidation compared to several standards.
\end{abstract}

\section{Introduction}

Fish oil originated from marine fish was enriched with omega-3, omega-6, eicosapentaenoic acid (EPA), docosahexaenoic acid (DHA) and polyunsaturated fatty acids (PUFA). Most of which cannot be synthesized naturally by the human body thus, necessitating daily or weekly consumption. Nowadays, sourcing fish oil from marine resources has been discouraged and limited. To overcome with this problem, freshwater fish has been seen as a potential source for fish oil. Compared to marine fish, freshwater fish contain high levels of $\mathrm{C} 18$ PUFA [1] meanwhile, ratio of $\omega-3: \omega-6$ fatty acids in total lipid of freshwater fish typically range from 0.5-3.8 [2]. In Thailand, there are many catfish processing industries. They face problems due to the negative environmental impact of their by-products from the catfish processing. The utilization of by-products from fish processing industry is considered an important clean production opportunity for the fish processing industry as it potentially generates additional revenue, reduces disposal costs of these materials and eliminates or reduces the environmental and health impacts of waste disposal [3]. In Thailand, catfish processing industries produce significant amount of waste. Utilization of catfish processing waste can be used to produce fish oil and numerous bioactive compounds. Therefore, extracting oil from catfish and its processing waste was interesting and may add value to wastes. Fish oil was usually obtained by various extraction techniques [4]. Several studied on methods and conditions for fish oil extraction have been conducted in the past including solvent extraction method
[5,] supercritical fluid extraction [6], soxhlet method [7], wet and steam rendering methods [8] and wet pressing method [9]. Among these techniques, wet pressing method is widely used for oil extraction in the industrial scale as described by Food and Agriculture Organization [9]. This process involves cooking the raw material, pressing and lastly centrifugation or filtration of miscella to recover oil. Currently, extraction using enzymes has increasing importance in the production of food supplements, fine chemicals, medicines. The study of a minimum amount of energy is required for the large-scale production. Enzymatic hydrolysis of fish sample is mainly performed to extract fish oil. Alcalase enzyme is one of the best enzymes used in hydrolysis process for fish oil [10]. However, the pretreatment process for oil extraction was necessary for improving the quantity and quality of oil. Microwave pretreatment technology has been widely used by several researchers as a potential method for pretreatment of various materials. Microwave heating is preferred over conduction/convection heating as it heats the target object directly by applying an electromagnetic field to dielectric molecules. Therefore, this technique can help to hydrolyse the enzymatic hydrolysis process. Microwave radiation causes molecular friction of electric dipoles, which results in heating. Lipids have a low specific heat, which makes them susceptible to this radiation [11]. Microwave preheating can be used to substitute conventional oven heating, resulting in quicker pretreating with less energy consumption. This generates permanent pores in the tissue, resulting in a higher yield [12]. Microwave pretreatment also improves oil quality. The short

\footnotetext{
a Corresponding author: thitiphan.cs@gmail.com
} 
exposure time to microwaves, as compared to oven cooking, preserves most thermolabile compounds from degradation reactions [13]. Among available and currently being-developed methods, microwave pretreatment is a method of choice because it is a simple technique for production of high quality oil as well as provision of highly nutritional values retention.

As far as it can be ascertained, there have been no published reports on the effects of microwave pretreatment on extraction yield and quality of catfish oil extracted from catfish processing waste in Northern Thailand. Therefore, this study aims to investigate the effect of microwave pretreatment on the catfish oil extraction operation by enzymatic hydrolysis and evaluate the fish oil quality.

\section{Materials and methods}

All reagents were of analytical grade and purchased from Merck. The alcalase enzyme used in this study was obtained from Sigma-Aldrich. Solvents were used without further purification. All wastes of hybrid strain of Pangasianodon gigas and Pangasianodon hypothalamus were obtained from Faculty of Fisheries Technology and Aquatic Resources, Maejo University, Chiang Mai and stored at $-40 \circ \mathrm{C}$ until further processed. All microwave tests were carried out with a sharp, model R-285 microwave oven working at $2450 \mathrm{MHz}$ with a power of $1.25 \mathrm{~kW}$. For each microwave pretreatment, $20 \mathrm{~g}$ of fish waste was arranged in a single layer in petri dishes. Sample was microwave-treated at a frequency of 2,450 $\mathrm{MHz}$ and time of radiation was $30 \mathrm{~s}$. Based on preliminary tests, we founded the treatments with microwave, combining two variables: two levels of potency $(0$ and $330 \mathrm{~W})$ and five times of extraction (30$150 \mathrm{~min}$ ). For microwave power and time of microwave pretreatment tests, we set up the treatments with microwave, combining two variables: three levels of potency $(110,330$ and $550 \mathrm{~W})$ and five times of radiation $(0-120 \mathrm{~s})$. The extraction time used the optimum condition from preliminary tests.

Later the samples microwave-treated corresponding to the three replicates were collected and permitted to cool to ambient temperature condition before oil extraction by enzymatic hydrolysis. The enzymatic hydrolysis of fish oil was described by Liaset et al. using alcalase enzyme [14]. About $20 \mathrm{~g}$ of sample from microwave pretreatment and non-pretreatment was weighed and extracted. Enzymatic hydrolysis was obtained by adding alcalase enzyme $2.0 \%$ by weight of sample. The process was carried out for $2 \mathrm{~h}$ at $120 \mathrm{rpm}$ [12]. The oil was collected and stored at $-20^{\circ} \mathrm{C}$. Analysis of the oil samples were determined as describes by AOAC methods. Peroxide value $(\mathrm{PV})$ was determined according to AOAC method 965.33 (AOAC, 2000). Samples was determined in triplicate and expressed as milliequivalent peroxide $/ \mathrm{kg}$ oil (meq $/ \mathrm{kg}$ ). $P$-anisidine value was determined according to AOCS Cd-18-90 method [15]. Analysis for acids value (AV) was determined according to AOAC method 940.28. AOAC method 993.20 was used to determine the iodine value. Fatty acid components were identified by gas chromatography equipped with a flame ionization detector (FID). The extractions and all analyses were executed at least in triplicate and data presentation was expressed as means and standard deviation. Values are means of three replicates SD. Means followed by different letters are significant different $(p<0.05)$.

\section{Results}

The effect of microwave pretreatment on oil extraction yield by enzymatic hydrolysis was carried out using fish processing waste with microwave pretreatment and nonpretreatment or untreated samples. The oil extraction yield by enzymatic hydrolysis was exhibited in Table 1 . At the extraction time of 30-150 min, oil extraction yield increased when microwave radiation was applied. The most appropriate extraction time for microwave pretreatment was found to be $30 \mathrm{~min}$, as it resulted in the maximum of extraction yield. Thus, an extraction time of 30 min was selected for this study. Untreated (Control) would require $150 \mathrm{~min}$ to achieve the same extraction yield compared to when it was produced by microwave pretreatment with a $30 \mathrm{~min}$ extraction time. This result was to be expected previously probably due to the fact that microwave pretreatment provides a potential alternative to induce stress reactions in plant systems or tissues [12]. Comparisons of oil yields of waste exposed to three microwave power levels $(110,330$ and $550 \mathrm{~W})$ for microwave pretreatment times $(0-120 \mathrm{~s})$ were demonstrated in Table 2. It was found that the oil extraction yield was increased significantly when microwave pretreatment times was increased from 0 to 60 s. However, further increased microwave pretreatment times from $90-120 \mathrm{~s}$ for microwave power $110 \mathrm{~W}$ did not show any significant improvement in oil extraction yield. Interestingly, the increased microwave pretreatment times higher than $90 \mathrm{~s}$ for microwave power $330 \mathrm{~W}$ and $30 \mathrm{~s}$ for microwave power $550 \mathrm{~W}$, the samples were burned. The effect of microwave power did not show any significant in oil extraction yield at the same time. Therefore, the optimum condition for microwave pretreatment was 110 $\mathrm{W}$ of microwave power for $60 \mathrm{~s}$ resulted in the highest $(9.25 \%)$. This result is in good agreement with a report made by Kittiphoom et al. who employed the optimum condition for pretreated in plant seed oil by a solvent extraction was microwave power of $300 \mathrm{~W}$ for $30 \mathrm{~s}$ [16]. Microwave pretreatment also improves oil quality. The short exposure time to microwaves, as compared to oven cooking, preserves most thermolabile compounds from degradation reactions. Physicochemical characteristics of fish oil were shown in Table 3 . Each value represented means of three repetitions. Acid value can be used as a purity examination of oil and showed that oil may have already started decomposition reactions. Acid value stayed relatively constant, as can be seen that untreated waste was $2.20 \%$ and microwave pretreatment waste was $2.35 \%$. Increment in the acid value of oil may be attributed to hydrolysis of triacylglycerol by microwave to produce more amount free fatty acids [17]. 
Table 1. Oil extraction yield from fish processing waste obtained by different extraction time.

\begin{tabular}{|c|c|c|c|c|c|}
\hline Condition & \multicolumn{5}{|c|}{ Extraction yield (\%) } \\
\hline & $30 \min$ & $60 \min$ & $90 \min$ & $120 \min$ & $150 \mathrm{~min}$ \\
\hline Non-pretreatment & $3.30 \pm 0.38^{\mathrm{a}}$ & $4.80 \pm 0.25^{\mathrm{b}}$ & $5.70 \pm 0.20^{\mathrm{c}}$ & $7.54 \pm 0.32^{\mathrm{d}}$ & $7.62 \pm 0.38^{\mathrm{d}}$ \\
Microwave 330 w & $7.61 \pm 0.32^{\mathrm{a}}$ & $7.51 \pm 0.35^{\mathrm{a}}$ & $7.59 \pm 0.47^{\mathrm{a}}$ & $7.53 \pm 0.26^{\mathrm{a}}$ & $7.48 \pm 0.20^{\mathrm{a}}$ \\
\hline
\end{tabular}

Table 2. Oil extraction yield from fish processing waste obtained by different time and microwave power. * Samples were burned.

\begin{tabular}{|c|c|c|c|c|c|}
\hline Microwave power & \multicolumn{5}{|c|}{ Extraction yield (\%) } \\
\hline & $0 \mathrm{~s}$ & $30 \mathrm{~s}$ & $60 \mathrm{~s}$ & $90 \mathrm{~s}$ & $120 \mathrm{~s}$ \\
\hline $110 \mathrm{~W}$ & $5.35 \pm 0.12^{\mathrm{c}}$ & $6.90 \pm 0.25^{\mathrm{b}}$ & $9.25 \pm 0.20^{\mathrm{a}}$ & $9.26 \pm 0.32^{\mathrm{a}}$ & $9.25 \pm 0.38^{\mathrm{a}}$ \\
$330 \mathrm{~W}$ & $5.25 \pm 0.38^{\mathrm{c}}$ & $7.01 \pm 0.35^{\mathrm{b}}$ & $9.16 \pm 0.47^{\mathrm{a}}$ & $9.19 \pm 0.26^{\mathrm{a}}$ & $-^{*}$ \\
$550 \mathrm{~W}$ & $5.35 \pm 0.12^{\mathrm{a}}$ & $7.05 \pm 0.26^{\mathrm{b}}$ & $-{ }^{*}$ & $-{ }^{*}$ \\
\hline
\end{tabular}

Table 3. Physicochemical properties of fish oil.

\begin{tabular}{|c|c|c|}
\hline Properties & Non-pretreatment & Microwave pretreatment \\
\hline Acid value & $2.20 \% \pm 0.38$ & $2.35 \% \pm 0.08$ \\
Peroxide value & $2.11 \pm 0.33$ & $2.21 \pm 0.15$ \\
(meq $/ \mathrm{kg}$ ) & & $75.10 \% \pm 0.51$ \\
Iodine value & $76.05 \% \pm 0.02$ & $10.05 \pm 0.15$ \\
$P$-anisidine value & $8.35 \pm 0.33$ & \\
$(\mathrm{mmol} / \mathrm{kg})$ & & \\
\hline
\end{tabular}

Peroxide value is employed to measure the quantity of peroxides in the oil; these substances are important intermediate product of oxidative reactions since they decompose via transition metal irradiation and due to elevated temperatures to form free radicals. Peroxide values were $2.11 \mathrm{meq} / \mathrm{kg}$ oil and $2.21 \mathrm{meq} / \mathrm{kg}$ oil for untreated waste and microwave pretreatment waste, respectively. The acceleration of oil oxidation during microwave heating observed by an increasing in peroxide value due to presence of reactive radicals that might be formed by exposure to microwaves. Iodine value is a method to determine the degree of unsaturation of triglycerides. Base on this study, iodine value for oil extraction of catfish was $76.05 \%$ and $75.10 \%$ for untreated waste and microwave pretreatment waste, respectively. $P$-anisidine value is secondary products from the oxidation process that determines the decreasing of peroxide values but increasing of anisidine value. It is represented by further degradation of lipids through a radical oxidation process initiated by hydro peroxides. This study showed that $p$-anisidine value was 8.35 $\mathrm{mmol} / \mathrm{kg}$ and $10.05 \mathrm{mmol} / \mathrm{kg}$ for untreated waste and microwave pretreatment waste, respectively. In addition, fatty acids compositions in fish oil were demonstrated in Table 4. Fatty acid composition of fish oil is very similar to what can be found in previous reports [18, 19]. However, differences in the fatty acid composition of fish oil are observed between an untreated oil sample and a microwave pretreated sample.

These results were similar to the effect of microwave treatment of fish waste on fish oil extraction. Oleic acid was the most abundant fatty acid in fish oil, $21.69 \%$ and $23.70 \%$ for untreated waste and microwave pretreatment waste, respectively. Moreover, palmitic acid was the second most abundant fatty acid in the samples and its range was between $16.21 \%$ and $15.65 \%$, for untreated waste and microwave pretreatment, respectively. Results shown in Table 4 demonstrated that microwave pretreatment affected the fatty acid compositions of fish oil.

Table 4. Fatty acids composition in catfish oil from nonpretreatment and microwave pretreatment.

\begin{tabular}{|l|c|c|}
\hline \multicolumn{1}{|c|}{ Fatty acids } & $\begin{array}{c}\text { Non- } \\
\text { pretreatment }\end{array}$ & $\begin{array}{c}\text { Microwave } \\
\text { pretreatment }\end{array}$ \\
\hline Palmitic acid & $16.21 \pm 0.70$ & $15.65 \pm 0.02$ \\
Stearic acid & $1.85 \pm 1.51$ & $1.78 \pm 0.35$ \\
Oleic acid & $21.69 \pm 1.43$ & $23.70 \pm 0.60$ \\
Linoleic acid & $1.75 \pm 1.70$ & $1.74 \pm 0.51$ \\
EPA & $7.20 \pm 0.30$ & $7.54 \pm 0.33$ \\
DHA & $8.40 \pm 0.60$ & $8.62 \pm 0.02$ \\
\hline
\end{tabular}

\section{Discussion}

The enzymatic extraction of oil was used in this study because of its advantages over chemical oil extraction. Rodriguez et al. [20] stated that enzymatic extraction of fish oil yields better results than other chemical extraction methods. The advantages include: low energy requirement, no use of solvent and low investment for a large scale process. The selection of enzyme plays an important role in the extraction of oil from fish and fish waste. Several enzymes (alcalase, neutrase, protamex and flavourzyme) can be used for the extraction of fish oil. However, researchers reported that alcalase was the best enzyme for the extraction of oil from fish and fish waste. Linder et al. studied effect of three enzymes (alcalase, neutrase and flavourzyme) on the extraction of oil from ground salmon heads, and reported that highest oil recovery was obtained from alcalase treated samples [21]. Slizyte et al. extracted fish oil from cod by-products using alcalase enzyme [22]. Gboguri et al. studied the enzymatic hydrolysis of the oil from salmon heads, using

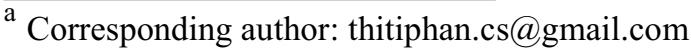


alcalase, neutrase and protamex and found that alcalase to be the most efficient enzyme for oil recovery. Batista et al. extracted fish oil from sardine by-products using three enzymes (alcalase, neutrase and protamex), and concluded that both alcalase and protamex were efficient for oil extraction [23]. Therefore, in this study, alcalase enzyme was chosen for the extraction of oil from catfish waste parts. The results revealed that alcalase enzyme can hydrolyze and produce catfish oil from the waste in the same percentage yield as the earlier fish oil production. Numerous different standards with varies acceptable levels for fish oil quality have been established. The objectives for all those standards are to control the quality of fish oil properties from potential biological and chemical hazards related to oxidation [24]. Oxidation of lipids lead to some disadvantage including rancid odor and flavor, reducing nutritional quality and safety $[25,26]$. Peroxide value (PV) is primary oxidation products that give sign for initial rancidity in the oil. According to European Food Saferty Authority (EFSA), peroxide value and acids value (AV) are recommended as chemical methods for determination of the oxidative status for crude fish oil and refined fish oil, as these methods are commonly used in the industry. U.S Food and Drugs Administration Generally Recognized as Safe (FDA GRAS) [27, 28], suggested that PV should be $<2.5$ $\mathrm{meq} / \mathrm{kg}$ and $\mathrm{AV}<1.0 \%$, meanwhile by Global Organization for EPA and DHA Omega-3s (GOED) [29] stated PV should $<5 \mathrm{meq} / \mathrm{kg}$. Refer to the Table III; PV and AV of both conditions meet the level of standard by FDA GRAS and GOED. $P$-anisidine value is secondary products from the oxidation process. These studies showed that $p$-anisidine value of both conditions was in the range to standard by FDA GRAS which was below 20 $\mathrm{mmol} / \mathrm{kg}[27,28,30]$ and $4-60 \mathrm{mmol} / \mathrm{kg}$ [31]. $P$-anisidine value gained by crude oil from carp (Cyprinus carpio) viscera was $10.3 \pm 0.3$ [32] a bit higher compared to treat waste with microwave pretreatment. Iodine value for oil extraction of catfish by using microwave pretreatment was 75.10 below than typical iodine values for fish oil, 120-180 [33] and iodine value by Bimbo [31]

\section{Conclusion}

The effect of microwave pretreatment on extraction oil yield and oil quality from catfish processing waste was investigated. The result revealed that a microwave pretreatment could be applied rather successfully to catfish oil extraction prior to extraction using enzyme hydrolysis by decreasing its extraction time. Pretreatment at $1 \mathrm{~min}$ and $110 \mathrm{~W}$ was considered as the most appropriate conditions of microwave pretreatment by decreasing extraction time from $150 \mathrm{~min}$ to up to $30 \mathrm{~min}$. The major advantage of microwave pretreatment is the reduced time of extraction, safety and energy consumption costs, when is compared to solvent extraction methods. Catfish oil was extracted by microwave pretreatment and enzymatic hydrolysis had lower lipid oxidation compared to several standards. These values are within the acceptable standards for edible fish oils and much better compared to several fish oil extraction methods. It suggested that microwave pretreatment can be used to help in oil extraction from the waste of catfish processing.

\section{Acknowledgements}

This work supported from Faculty of Science, Department of Chemistry, Applied Chemistry, Maejo University, Thailand.

\section{References}

1. R.G. Ackman, Comp. Biochem. Physiol 22, 907-922 (1967)

2. A.O. Osibona, K. Kusemijul and G. R. Akande, Afr. J. Food Agric. Nutr. Dev 9, 608-621 (2009)

3. S.A. Ioannis and K. Aikaterini, Int. J. Food. Sci. Technol 43, 726-745 (2008)

4. S.J. Iverson, S.L.C. Lang and M.H. Cooper, Lipids 36, 1283-1287 (2011)

5. C.F. Moffat, A.S. McGiU, R. Hardy and R.S. Anderson, J. Am. Oil. Chem. Soc 70, 133-138 (1993)

6. N.T. Dunford, F. Temelli, and E. LeBlanc, J. Food. Sci 62, 289-294 (1997)

7. S. Ferdosh, Z. I. Sarker, N. Norulaini, A. Oliveira, K. Yunus, A. J. Chowdury, J. Akanda and M. Omar, J. Food Process Pres 38, 1-9 (2015)

8. S. Chantachum, S. Benjakul, N. Sriwirat, Food Chem 69, 289-294 (2000)

9. FAO, F. I. D., FAO fisheries technical paper, 142, 63 (1986)

10. R. Slizyte, T. Rustad and I. Storro, Process Biochem 40, 3680-3692 (2005)

11. E. Chiavaro, M. T. Rodriguez-Estrada, E. Vittadini, and N. Pellegrini, LWT-Scie. Tech 43, 1104-1112 (2010)

12. S. Azadmard-Damirchi, F. Habibi-Nodeh, J. Hesari, M. Nemati, and B. F. Achachlouei, Food Chem 121, 1211-1215 (2009)

13. F. Amarni, and H. Kadi, Innov. Food Sci. Emerg 11, 322-327 (2009)

14. B. Liaset, E. Lied and M. Espe J. Sci. Food Agric 80, 581$589(2000)$

15. AOCS (American oil chemists' society), Official methods and recommended practices of the American oil chemists' society, 4th ed. (1989)

16. S. Kittiphoom and S. Sutasinee, Int. Food Res. J 22, 960$964(2015)$

17. F. Anjum, F. Anwar, A. Jamil and M. Iqbal, J. Am. Oil. Chem Soc 83, 777-784 (2006)

18. V.V. Ramakrishnan, A.E. Ghaly, M.S. Brooks and S.M. Budge, Enz. Eng 2, 2-10 (2013)

19. H. Yoshida, Y. Hirakawa, Y. Tomiyama and Y. Mizushina, Eur. J. lipid sci. technol 105, 351-358 (2003)

20. NR. Rodriguez, S. Beltran, I. Jaime, SM. de Diego, MT. Sanz, Innov. Food Sci. Emerg. Technol 11, 1-12 (2010)

21. M. Linder, J. Fanni, M. Parmentier, Mar Biotechnol 7, 70-76 (2005)

22. R. Slizyte, T. Rustad, I. Storrro, Process Biochem $\quad 40$, 3680-3692 (2005)

23. I. Batista, C. Ramos, R. Mendonca, ML. Nunes, J. Aquat. Food Prod. Technol 18, 120-134 (2009)

24. G. Boran, H. Karacam, M Boran. Food Chem 98, 693-698 (2006)

25. E.N. Frankel. Food Chem 57, 51-55 (1996)

26. K.P. Suja, J.T. Abraham, S.N. Thamizh, A. Jayalekshmy and C. Arumughan. Food Chem 84, 393-400 (2004) 
27. FDA GRAS Notification, GRAS Notice 000105: online available from www. accessdata.fda.gov/acripts, (2002)

28. FDA GRAS Notification, GRAS Notice 000200. Online available from www.accessdata.fda.gov/acripts, (2006)

29. Global Organization for EPA and DHA omega-3s (GOED). GOED Voluntary Monograph 3, (2006)
30. R.J. Hamilton, C. Kalu, G.P. McNeill,F.B. Padley, and J.H. Pierce. J. Am. Oil. Chem. Soc 75, 813-882 (1988)

31. A.P. Bimbo, Inform 9, 473-483 (1998)

32. V. T. Crexi, M. L. Monte, L. A. S. Soares, L. A. A. Pinto, Food Chem 119, 945-950 (2010)

33. V.Y. A. Barku, H.D Nyarko and P. Dordunu. Food. Sci. Qual. Manag 8, 9-17 (2012) 